\title{
Distribuição espacial de um fragmento de Floresta Ombrófila Mista Montana
}

\author{
Spatial distribution of a Mixed Ombrophylus Forest fragment
}

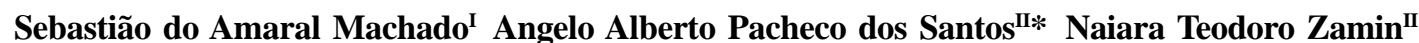 \\ Rodrigo Geroni Mendes Nascimento ${ }^{\text {II }}$
}

\section{RESUMO}

Este trabalho teve como objetivo analisar a distribuição espacial de um fragmento de Floresta Ombrófila Mista Montana, bem como de três espécies de grupos sucessionais distintos pertencentes a ela, pela função $K$ de Ripley. Os dados utilizados provêm de um censo realizado em um fragmento localizado no Campus Jardim Botânico da $U F P R$, Curitiba-PR, onde todas as árvores com DAP acima de $10 \mathrm{~cm}$ foram georreferenciadas. Foi utilizada uma parcela de 4 ha para a análise da distribuição espacial da floresta bem como das espécies de Araucaria angustifolia (Bertol.) O. Kuntze (Araucária), Casearia Sylvestris Sw. (Cafezeiro) e Cedrela fissilis Vell. (Cedro). Foi analisada a relação espacial entre as espécies, bem como a relação espacial entre classes diamétricas destas. A floresta apresentou uma distribuição espacial aleatória, entretanto, as três espécies selecionadas apresentaram um padrão espacial agregado, quando analisadas separadamente. O Cafezeiro apresentou relação de atração com a Araucária e com o Cedro; estes, por sua vez, apresentaram relação de repulsão entre si. A relação espacial entre classes de DAP da Araucária foi de atração entre os indivíduos de classes menores com os indivíduos maiores. Este resultado reflete a forma de dispersão de sementes das espécies, em que a regeneração ocorre em proximidade às árvores parentais. Para o cafezeiro e o Cedro, ocorreu agregação apenas entre os indivíduos menores.

Palavras-chave: função $k$ de Ripley, floresta com araucária, grupos sucessionais.

\section{ABSTRACT}

The objective of this research was to analyze the spatial distribution of a Mixed Ombrophylus Forest fragment, as well as of three species pertaining to distinct successional groups belonging to the same, by the Ripley's K function. The data came from a census carried out in a fragment located in the Campus Botanical Garden, UFPR, Curitiba - PR, Brazil, where all trees with $\mathrm{DBH}$ above $10 \mathrm{~cm}$ were georeferenced. One plot with 4 ha was used for the analysis of the spatial distribution of the forest and individually for the species of Araucaria angustifolia (Bertol.) O. Kuntze, Casearia Sylvestris Sw. and Cedrela fissilis Vell. The spatial relationship between species, as well as the spatial relationship between diameter classes of the same were also analyzed. The forest showed a random spatial distribution, however, the three selected species showed an aggregate spatial distribution when analyzed individually. The Casearia Sylvestris presented an attraction relationship with Araucaria angustifolia and Cedrela fissilis, and these trees in turn, were related to repulsion between them. The spatial relationship between $\mathrm{DBH}$ classes of Araucaria angustifolia was attraction between individuals of smaller classes with larger individuals. This result reflects the form of seed dispersal of species, where regeneration occurs in the proximity to the parental trees. For the Casearia Sylvestris and Cedrela fissilis, aggregation occurred only between the smaller individuals.

Key words: ripley's $k$ function, araucaria forest, successional groups.

\section{INTRODUÇÃO}

A Floresta Ombrófila Mista compreende as formações vegetacionais típicas dos planaltos da região sul do Brasil que originalmente ocupava uma área de aproximadamente 20 milhões de hectares e, devido à grande exploração dessas florestas ao longo dos anos, esta área foi reduzida a 2.506 .485 hectares

\footnotetext{
IDepartamento de Ciências Florestais, Universidade Federal do Paraná (UFPR), Curitiba, PR, Brasil.

IIPrograma de Pós-graduação em Engenharia Florestal, UFPR, Av. Prefeito Lothário Meissner, 632, 80210-170, Curtiba, PR, Brasil. E-mail: angelopachecos@gmail.com. *Autor para correspondência.
} 
distribuídos entre florestas secundárias em estágio inicial, médio e avançado de sucessão (SANQUETTA et al., 2001). Atualmente, essa pequena porção de floresta remanescente está dispersa sob a forma de pequenos fragmentos, também conhecidos como capões.

Segundo SCHAAF et al. (2006), para que a floresta Ombrófila Mista seja efetivamente preservada e continue oferecendo seus benefícios diretos e indiretos, não basta apenas o enrijecimento das leis ambientais, sendo também necessário gerar conhecimento acerca da estrutura dos remanescentes dessa formação florestal, auxiliando, assim, a elaboração de novas técnicas de manejo que permitam conservar e utilizar racionalmente esses recursos.

A distribuição espacial das espécies é uma ferramenta que auxilia na compreensão dos seus aspectos ecológicos, possibilitando analisar resultados que podem ajudar na compreensão da dependência espacial das espécies e do seu padrão de distribuição, fornecendo subsídios importantes para técnicas de manejo sustentável da floresta, auxiliando ainda em processos de amostragem e monitoramento de espécies vegetais em unidades de conservação (PEREIRA et al., 2006). Dentre os diversos métodos de análise da distribuição espacial de espécies e formações florestais, destaca-se a função K de Ripley (BATISTA \& MAGUIRE, 1998; ANJOS et al., 2004; SILVAet al., 2008; RODE et al., 2010). Esta função consiste em um método baseado em contagem e distância que utiliza as coordenadas (x, y) de cada árvore existente na área de estudo. O método possui ainda a vantagem de avaliar a distribuição espacial em diferentes escalas (RIPLEY, 1977). Por meio da estimativa da função univariada de $\mathrm{K}$, é possível testar a hipótese de Completa Aleatoriedade Espacial, em que é investigado se o padrão de distribuição espacial das espécies se comporta de forma agregada, aleatória ou regular. A função K bivariada, por sua vez, analisa a hipótese de Completa Independência Espacial, a qual informa se a relação entre dois grupos de árvores é de atração, independência ou inibição.

Este estudo teve como objetivo analisar a distribuição espacial de um fragmento de Floresta Ombrófila Mista Montana, bem como de três espécies de grupos sucessionais distintos pertencentes a ela, utilizando a função K de Ripley.

\section{MATERIAL E MÉTODOS}

A área de estudo compreende um fragmento de Floresta Ombrófila Mista, situado em Curitiba - PR

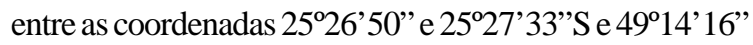

e 49¹4'33”'W, a aproximadamente $900 \mathrm{~m}$ de altitude. A área total do remanescente estudado é de aproximadamente 15,24ha, sendo 12,96ha ocupados por Floresta Ombrófila Mista (RONDON NETO et al., 2002). Segundo classificação de Koppën, o clima é classificado como Cfb: subtropical úmido mesotérmico de verões frescos, inverno com geadas frequentes, sem estação seca. As temperaturas médias anuais nos meses quentes e frios são inferiores a 22 e $18^{\circ} \mathrm{C}$, respectivamente, sendo a temperatura média anual de $17^{\circ} \mathrm{C}$. A precipitação média anual é de $1250 \mathrm{~mm}$, distribuídos por todo o ano. Verificou-se a existência de Gleissolos próximos aos canais de drenagem e de Cambissolos e Argissolos nas regiões mais drenadas (RONDON NETO et al., 2002).

A escolha das espécies que compõem este estudo baseou-se nos seus aspectos ecológicos e na frequência destas na área de estudo. Dessa forma, dentre as espécies de maior valor de cobertura, foi selecionada uma espécie de cada grupo sucessional, segundo o modelo de classificação ecofisiológico sugerido por BUDOWSKI (1965). Segundo este autor, as espécies são classificadas, segundo o estágio sucessional, como: pioneiras, secundárias iniciais, secundárias tardias e clímax.

Araucaria angustifolia (Bertol.) O. Kuntze, popularmente chamada de Araucária, foi escolhida para o estudo por ser uma espécie secundária tardia (LAMPRECHT, 1990), característica da Floresta Ombrófila Mista, apresentando valor de cobertura de 30,6\% na área de estudo. Trata-se de uma espécie marcadora da fisionomia da vegetação, ocupando o estrato superior da floresta. O Cafezeiro (Casearia sylvestris Sw.) foi escolhido por se tratar de uma espécie pioneira típica de florestas alteradas (DIAS et al., 1998) apresentando um valor de cobertura de 25,8\% na área de estudo. Por fim, foi selecionado o Cedro (Cedrela fissilis Vell.), o qual apresentou um valor de cobertura de 6,2\% no fragmento estudado. Trata-se de uma espécie secundaria inicial (VACCARO et al., 1999) que se desenvolve no interior de florestas primárias, mas que apresenta agressividade na vegetação secundária.

Os dados utilizados nas análises provieram de censo, ou inventário a 100\%, realizado no capão durante os anos de 2006 e 2007. Para realização do censo, a área foi dividida em blocos de 50x50m, os quais foram georreferenciados a partir do norte de quadrícula de um mapa da região e materializados em campo com o uso de teodolito. Todos os indivíduos com diâmetro à altura do peito (DAP) acima de $10 \mathrm{~cm}$, foram medidos, identificados, plaqueteados e georreferrenciados a partir do vértice de cada bloco. 
Para realização da análise da distribuição espacial, foi utilizada uma parcela de 4ha (200x200m) alocada no estrato principal do capão. Esta parcela foi alocada de forma a ser representativa de todas as espécies estudadas e estar fora das áreas de influência da bordadura. Os dados de coordenadas $(\mathrm{x}, \mathrm{y})$ das árvores foram tratados como um evento dentro da parcela, para aplicação da função k de Ripley. Foram utilizados os dados de 92 indivíduos de Cedro, 107 indivíduos de Araucária, 589 indivíduos de Cafezeiro e 740 indivíduos para a floresta, respectivos a um total de 204, 335, 1.390 e 9.837 árvores, as quais compõem o banco de dados do censo do Capão da Engenharia Florestal (MACHADO et al., 2009).

Foi testada a hipótese da Completa Aleatoriedade Espacial (CAE) para as três espécies selecionadas e para a floresta como um todo. Foi testada ainda a Completa Independência Espacial (CIE) entre as espécies selecionadas e entre as classes de diâmetro de cada espécie. Na avaliação de CAE e CIE, foram construídos envelopes de confiança a partir de 100 simulações Monte Carlo, sendo, portanto, testadas as hipóteses a um nível de confiança de 99,0\%. A janela de distância s(m) utilizada nesta pesquisa foi de 100 metros, ou seja, a metade de um dos lados da parcela. As análises foram geradas usando o software Spatial Point Pattern Analysis (SPPA), versão 2.0.

As análises são realizadas graficamente: o envelope de confiança é identificado por duas linhas limites, uma positiva e outra negativa. Para aceitar a hipótese de Completa Aleatoriedade Espacial, a linha indicando os valores de $\mathrm{K}$ deve permanecer dentro do envelope de confiança, caso contrário a hipótese de aleatoriedade espacial é rejeitada e assume-se que o padrão de distribuição dos indivíduos é agregado, quando passar do limite superior do envelope (valores positivos), e regular, quando passar do limite inferior (valores negativos). De forma análoga à função univariada, a hipótese de Completa Independência Espacial é aceita quando o valor de k permanece dentro dos limites do envelope de confiança, caso contrário, assume-se que a relação espacial entre as espécies é de atração (k positivo), ou inibição (k negativo).

\section{RESULTADOS E DISCUSSÃO}

A distribuição espacial de todos os indivíduos dentro da parcela de 4ha, bem como das espécies selecionadas para o estudo são apresentadas na figura 1. Foi possível observar uma maior densidade de indivíduos de Cafezeiro em comparação as outras duas espécies.
Pela análise dos envelopes de confiança (Figura 2), foi possível observar que a distribuição espacial da floresta atende à hipótese da Completa Aleatoriedade Espacial, pois o valor de k permanece dentro do intervalo de confiança. Portanto, a floresta apresentou um padrão aleatório de distribuição espacial. As três espécies selecionadas para o estudo apresentaram um padrão de distribuição agregado, em uma escala de 70m para a Araucária e o Cafezeiro e em toda a janela de observação para o Cedro.

Os envelopes de confiança da função bivariada para a análise da CIE entre as espécies selecionadas são apresentados na figura 3. O Cafezeiro e o Cedro apresentaram relação espacial de atração em uma escala de até $80 \mathrm{~m}$. Da mesma forma, a Araucária e o Cafezeiro apresentaram relação de atração, porém em uma escala de até 40m. AAraucária e o Cedro, por sua vez, apresentaram relação espacial de repulsão ou inibição entre si.

A análise da Completa Independência Espacial entre classes de DAP da Araucária revelou uma relação de atração entre os indivíduos de classes diamétricas inferiores. Também foi encontrada relação de atração dos indivíduos da primeira classe diamétrica com os indivíduos da última classe. As classes superiores da Araucária apresentaram relação aleatória ou independente. O Cedro apresentou relação de atração apenas entre as classes de diâmetro menores. O Cafezeiro apresentou relação espacial de repulsão entre os indivíduos das classes maiores com os indivíduos menores.

As três espécies tratadas separadamente apresentaram padrão agregado de distribuição. Segundo HUBBELL (1979), padrões agregados, sobretudo em função da grande concentração de árvores jovens, são mais comuns em florestas tropicais do que padrões aleatórios. O mesmo padrão foi encontrado por ANJOS et al. (2004) ao analisarem a distribuição da Araucária. RODE et al. (2010), analisando a distribuição espacial da Araucária e das espécies de maior valor de cobertura em uma Floresta Ombrófila Mista, também encontraram o predomínio do padrão agregado.

A função $\mathrm{K}$ bivariada torna possível investigar a relação espacial entre duas espécies competidoras em potencial. A relação espacial entre as espécies estudadas neste trabalho sugerem que a luz pode ser o fator predominante de competição entre estas espécies. O Cafezeiro, apesar de ser uma espécie pioneira agressiva em pastagens, se desenvolve bem em florestas secundárias com baixa luminosidade (DIAS et al., 1998), e apresentou relação de atração com o Cedro e com a Araucária, ambas espécies dominantes 

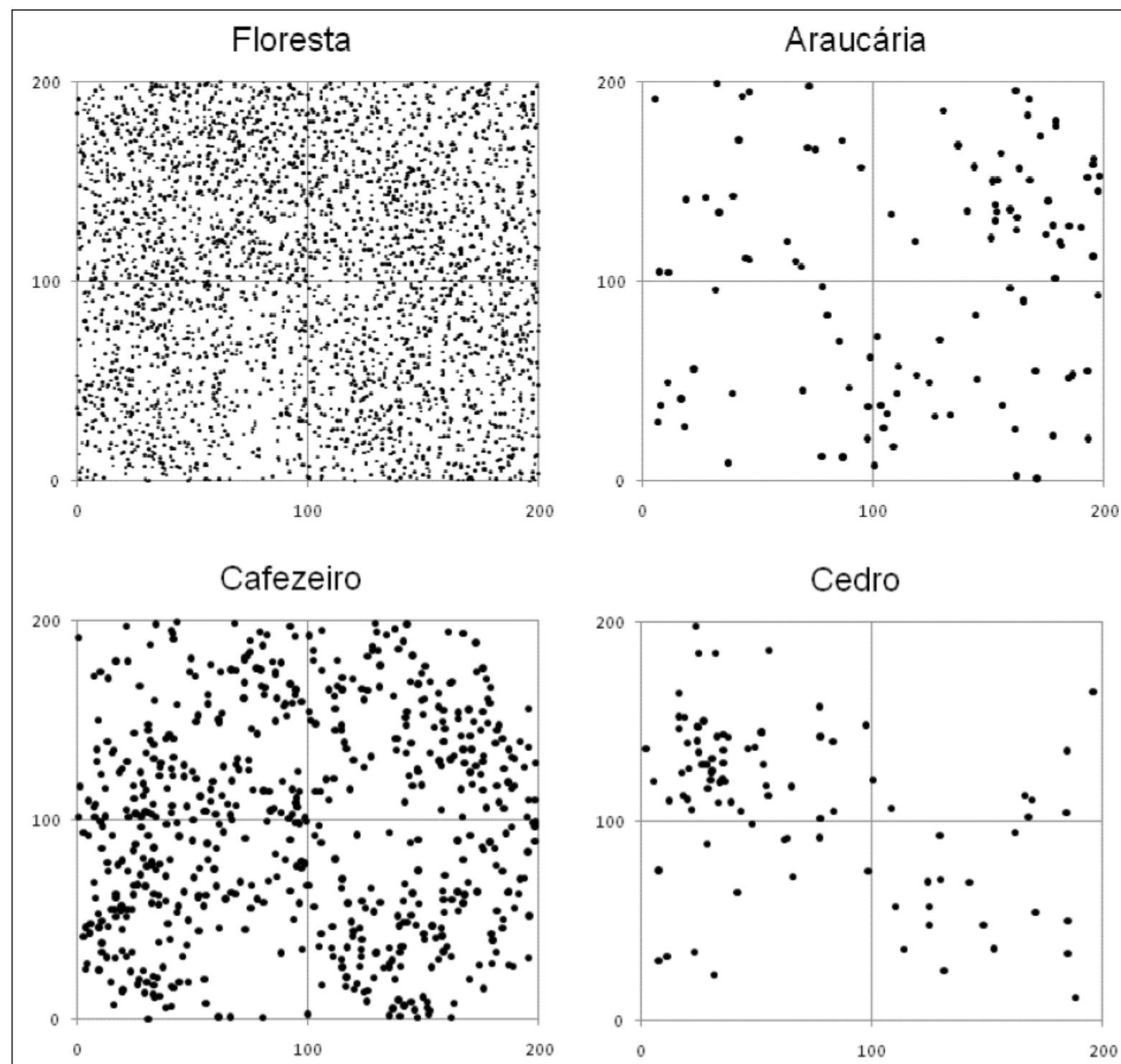

Figura 1 - Mapa da distribuição espacial da floresta e das espécies selecionadas dentro da parcela de 4ha, fragmento de Floresta Ombrófila Mista, Curitiba - PR.

do dossel. Analisando a relação espacial entre a Araucária e o Cedro, verificou-se inibição ou repulsão entres essas espécies, indicando uma possível competição pelo dossel, já que ambas são espécies exigentes em luz que regeneram em clareiras. RODE et al. (2010), analisando a relação espacial entre Psychotria Vellosiana, Myrsine umbellata e Alchornea triplinervia, encontraram uma relação de repulsão entre estas, argumentando que isto pode ser explicado em parte por estas espécies possuírem características ecológicas semelhantes. No entanto, os autores ressaltam que apenas a avaliação da sucessão e da dispersão ainda não são suficientes para explicar a relação espacial entre as espécies, sendo necessário ainda o conhecimento sobre quais restrições ambientais estão atuando, tais como luz, água, $\mathrm{CO}_{2}, \mathrm{~N}$, $\mathrm{P}, \mathrm{K}, \mathrm{Ca}, \mathrm{Mg}, \mathrm{S}$, entre outras.

Através da análise da CIE entre classes de diâmetro das três espécies estudadas, observou-se uma possível influência da capacidade de dispersão de sementes e da competição intra-específica na distribuição espacial destas espécies. Observou-se uma tendência à agregação para as espécies que possuem dispersão com alcance relativamente limitado. BUSING (1998), analisando o padrão espacial por classes de tamanho, observou que as árvores das classes menores, 

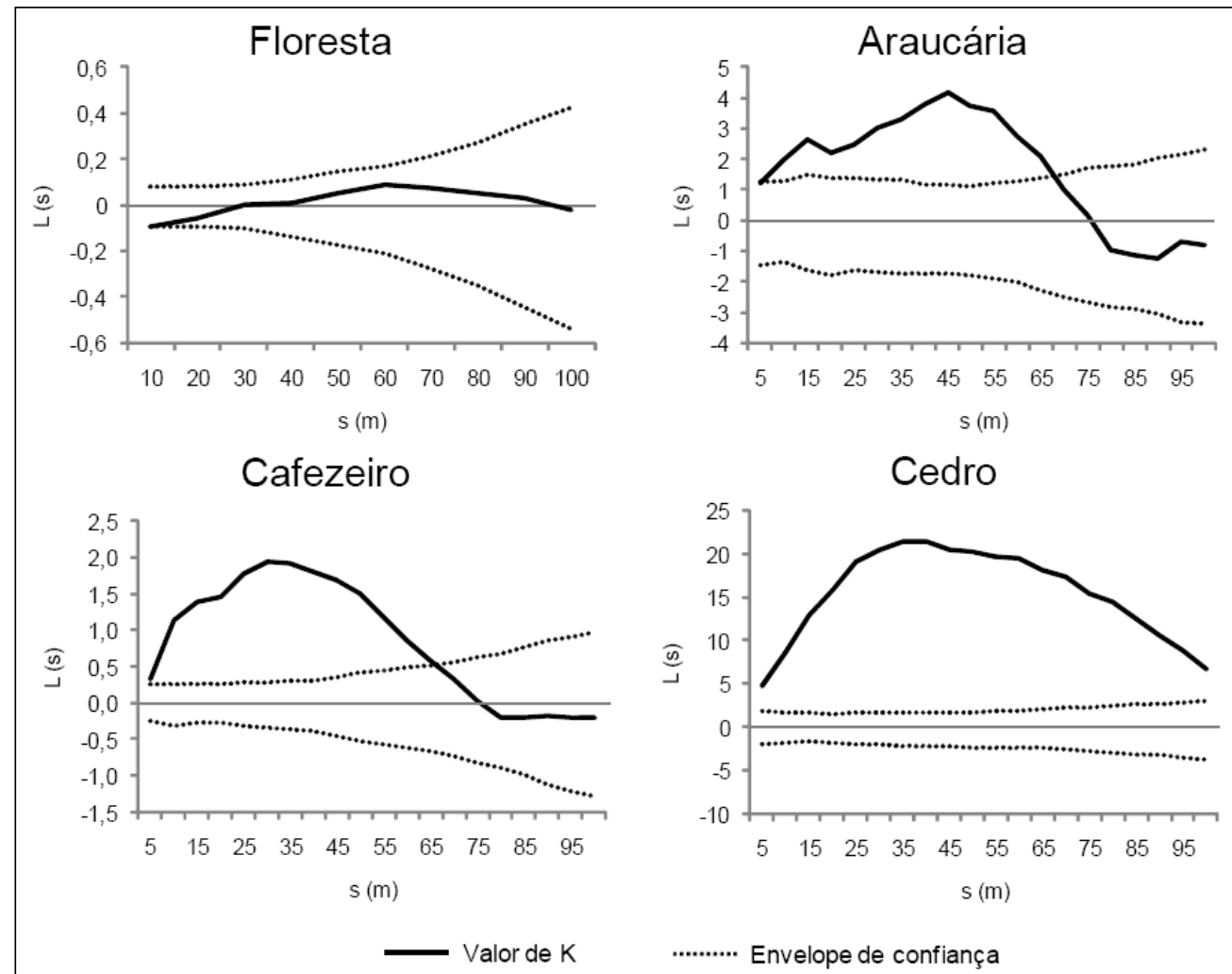

Figura 2 - Envelopes de confiança da função univariada para a análise da CAE da floresta e das três espécies selecionadas, fragmento de Floresta Ombrófila Mista, Curitiba - PR. Em que: s(m) = distância de observação da análise, $\mathrm{L}(\mathrm{s})$ = função transformada de $\mathrm{K}(\mathrm{s})$.

onde provavelmente estão incluídas as árvores jovens, mostram acentuada agregação, e que árvores de classes maiores apresentam tendência a padrões aleatórios. Esse autor argumenta ainda que a tendência de agregação de árvores jovens e sua afinidade com árvores adultas é resultado direto da limitada capacidade de dispersão, que faz com que a maioria das sementes e frutos produzidos fique no solo próximo à árvore de origem. No presente estudo, a Araucária apresentou resultado semelhante, possivelmente devido às características de dispersão dessa espécie, que se dá principalmente pela ação da gravidade, fazendo com que a regeneração ocorra próxima às árvores parentais (CARVALHO, 2003).

O Cedro, que possui dispersão principalmente anemocórica (ALCÁNTARA et al., 1997), apresentou agregação apenas entre os indivíduos menores. Isto sugere que a regeneração ocorre em mosaicos, porém afastada das árvores parentais. Com o crescimento das árvores e o consequente aumento da competição, a relação espacial entre as árvores toma uma conformação aleatória. O
Cafezeiro, disperso principalmente por pássaros (POTT \& POTT, 1994), apresentou relação espacial de repulsão entre os indivíduos maiores e os de menor porte diamétrico. Esse resultado sugere um comportamento similar ao do Cedro, em que a agregação ocorre apenas entre os indivíduos mais jovens. SILVA et al. (2008) observou resultado semelhante para a candeia (Eremanthus erythropappus), uma espécie pioneira de dispersão anemocórica, que apresentou padrão de distribuição aleatório entre as árvores adultas e os indivíduos mais jovens, ocorrendo agregação apenas entre os indivíduos de menor porte. PEREIRA et al. (2006) encontraram o mesmo padrão para o Jequitibá Rosa (Cariniana legalis), que apresentou padrão de distribuição aleatório entre as árvores adultas e as regenerantes. Esses autores argumentam que este resultado pode ser explicado devido à dispersão anemocórica das sementes.

\section{CONCLUSÃO}

O Fragmento de Floresta Ombrófila Mista apresentou padrão de distribuição espacial aleatório,

Ciência Rural, v.42, n.6, jun, 2012. 


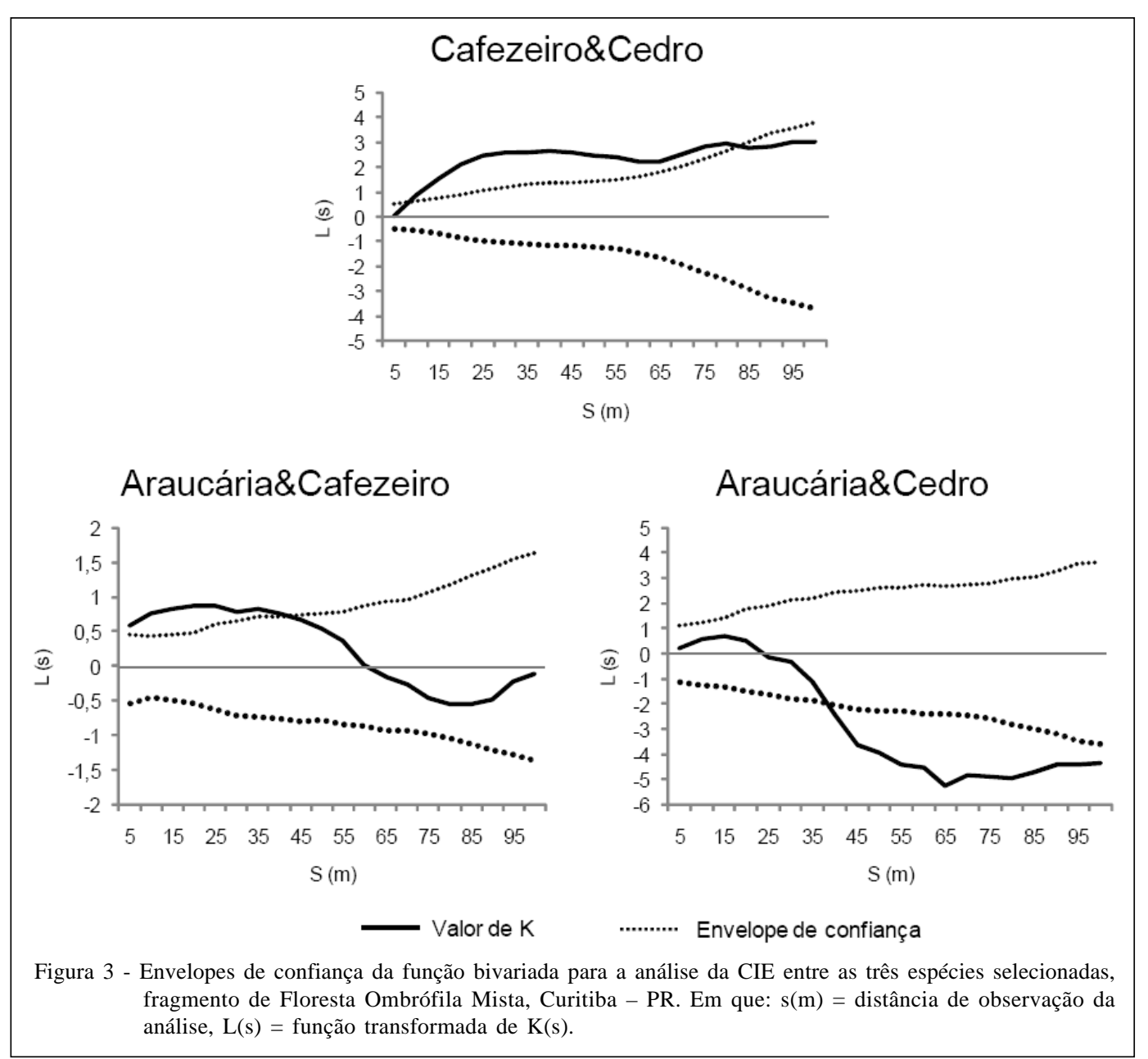

entretanto, as três espécies estudadas separadamente (Araucária, Cafezeiro e Cedro) apresentaram padrão de distribuição espacial agregado; o Cafezeiro apresentou relação espacial de atração com a Araucária e com o Cedro; estes por sua vez, demonstraram relação de repulsão entre si.

Concluiu-se também que há uma relação de atração entre os indivíduos menores de Araucária com os de maior porte. Para o Cedro, ocorreu agregação apenas entre as classes diamétricas menores; o Cafezeiro, por sua vez, apresentou uma relação de inibição entre os indivíduos de maior e de menor porte diamétrico.

\section{REFERÊNCIAS}

ALCÁNTARA, J.M. et al. Análise de la dispersión de semillas de Cedrela fissilis en el bosque nativo de Misiones. Yvyraretá, n.8, p.16-21, 1997.

ANJOS, A. et al. Análise do padrão de distribuição espacial da araucária (Araucaria angustifolia) em algumas áreas no Estado do Paraná, utilizando a função K de Ripley. Scientia Forestalis, n. 66, p. 38-45, dez. 2004. Disponível em: <http://www.ipef.br/ publicacoes/scientia/nr66/cap03.pdf >. Acesso em: 20 jun. 2011.

BATISTA, J.L.F.; MAGUIRE, D.A. Modelling the spatial structure of tropical forests. Forest Ecology and Management, v.110, p.293-314, 1998. Disponível em: <http:/ /www.mendeley.com/research/modeling-the-spatial-structureof-topical-forests/>. Acesso em: 20 jun. 2011.

BUDOWSKI, G. Distribution of tropical American rain forest species in the light of sucessional processes. Turrialba, v.15, n.1, p.40-42, 1965. Disponível em: <http://orton.catie.ac.cr/ cgi-bin/wxis.exe/?IsisScript=ORTON.xis\&method=post\& formato $=2 \&$ cantidad $=1 \&$ expresion $=m f n=017997>$. Acesso em: 20 jun. 2011.

BUSING, R.T. Composition, structure and diversity of cove forest stands in the Great Smoky Mountains: a patch dynamcis perspective. Journal of Vegetation Science, v.9, p.881890, 1998. Disponível em: <http://www.jstor.org/pss/3237053>. Acesso em: 20 jun. 2011.

CARVALHO, P.E.R. Espécies arbóreas brasileiras. Brasília: Embrapa Informação Tecnológica; Colombo/PR: Embrapa Florestas, 2003. V.1, 1039p. 
DIAS, M.C. et al. Composição florística e fitossociologia do componente arbóreo das florestas ciliares do Rio Iapó, na Bacia do Rio Tibagi, Tibagi, PR. Revista Brasileira de Botânica, v.21, n.2, p.183-195, 1998. Disponível em: <http:// www.scielo.br/scielo.php?script=sci_arttext\&pid=S0100 84041998000200011>. Acesso em: 20 jun. 2011. doi: 10.1590/ S0100-84041998000200011.

HUBBELL, S.P. Tree dispersion, abundance and diversity in a tropical dry forest. Science, v.203, p.1299-1309, 1979 Disponível em: <http://www.sciencemag.org/content/203/4387/ 1299.full.pdf $>$. Acesso em: 20 mar. 2010. doi: 10.1126/ science.203.4387.1299.

LAMPRECHT, H. Silvicultura nos trópicos: ecossistemas florestais e respectivas espécies arbóreas: possibilidades e métodos de aproveitamento sustentado. Eschborn: Instituto de Silvicultura da Universidade de Göttingen, GTZ, 1990. 343p.

MACHADO, S.A. et al. Funções de distribuição diamétrica em um fragmento de Floresta Ombrófila Mista. Ciência Rural, v.39, p.2428-2434, 2009. Disponível em: <http://www.scielo.br/

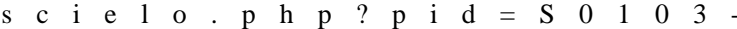
84782009000800024\&script $=$ sci_arttext $>$. Acesso em: 10 jul. 2010. doi: 10.1590/S0103-84782009000800024

PEREIRA, A.A. et al. Análise da distribuição espacial de Jequitibá Rosa em uma Floresta Estacional Submontana. Rev. Academica, v.4, n.2, p.21-34, 2006. Disponível em: <http://www2.pucpr.br/ reol/index.php/ACADEMICA/view/?dd1=1006>. Acesso em: 20 jun. 2011.

POTT, A.; POTT, V.J. Plantas do Pantanal. Corumbá: EMBRAPA - CPAP / Brasília: EMBRAPA - SPI, 1994. 320p.

RIPLEY, B.D. Modelling spatial patterns. Journal of the Royal Statistic Society, v.39, p.172-212, 1977. Disponível em: <http://www.jstor.org/pss/2984796>. Acesso em: 20 jun. 2011.
RODE, R. et al. Análise do padrão espacial de espécies e de grupos florísticos estabelecidos em um povoamento de Araucaria Angustifolia em uma floresta ombrófila mista no Centro-Sul do Paraná. Floresta, v.40, n.2, p.255-268, 2010. Disponível em: <http://ojs.c3sl.ufpr.br/ojs2/index.php/floresta/ article/view/17821/11623>. Acesso em: 20 jun. 2011.

RONDON NETO, R.M et al. Caracterização florística e estrutural de um fragmento de Floresta Ombrófila Mista, em Curitiba, PR - Brasil. Revista Floresta, v.32, n.1, p.3-16, 2002. Disponível em: <http://ojs.c3sl.ufpr.br/ojs2/index.php/ floresta/article/view/2366/1978>. Acesso em: 20 jun. 2011.

SANQUETTA, C.R. et al. Dinâmica da estrutura horizontal de um fragmento de Floresta Ombrófila Mista no Centro-Sul do Paraná. Revista de Ciências Exatas e Naturais, v.3, n.1, p.43-47, 2001. Disponível em: <http://www.unicentro.br/ editora/revistas/recen/v3n1/Dinamica.pdf $>$. Acesso em: 10 jun. 2011.

SCHAAF, L.B. et al. Alteração na estrutura diamétrica de uma floresta ombrófila mista no período entre 1979 e 2000. Revista Árvore, v.30, n.2, p.283-295, 2006. Disponível em: <http:// www.scielo.br/scielo.php?script $=$ sci_arttext \&pid $=$ S010067622006000200016\&lng=en\&nrm=iso $>$. Acesso em: $10 \mathrm{jul}$. 2010. doi: 10.1590/S0100-67622006000200016.

SILVA, M.A. da et al. Análise da distribuição espacial da candeia (Eremanthus erythropappus (DC.) MacLeish) sujeita ao sistema de manejo porta-sementes. Cerne, v.14, n.4, p.311-316, 2008. Disponível em: <http://redalyc.uaemex.mx/src/inicio/ ArtPdfRed.jsp?iCve=74411119004>. Acesso em: 10 jul. 2010.

VACCARO, S. et al. Aspectos da composição florística e categorias sucessionais do estrato arbóreo de três subseres de uma floresta estacional decidual, no Município de Santa Tereza - RS. Ciência Florestal, v.9, n.1, p.1-18, 1999. Disponível em: <http://www.ufsm.br/cienciaflorestal/artigos/v9n1/ art1v9n1.pdf>. Acesso em: 20 jun. 2011. 